\title{
FLUTUAÇÃO POPULACIONAL E CONTROLE DA MARIPOSA ORIENTAL (Grapholita molesta Busck, 1916) EM PRODUÇÃO CONVENCIONAL E INTEGRADA DE PESSEGUEIRO ${ }^{1}$
}

\author{
JOSÉ LUIS DA SILVA NUNES², ROSELI DE MELLO FARIAS ${ }^{3}$, DENIS SALVATI GUERRA ${ }^{4}$, VINÍCIUS GRASSELLI $^{5}$, \\ GILMAR ARDUINO BETTIO MARODIN ${ }^{6}$
}

RESUMO - Este trabalho foi realizado nos anos de 2000 e 2001, em um pomar comercial de pessegueiro 'Marli', no município de São Jerônimo, RS, latitude 3005' 52”' S, longitude 51³9'08” 'W e altitude de 46 metros. A população de Grapholita molesta (Busck, 1916) foi monitorada com o objetivo de comparar as técnicas de controle preconizados no sistema de Produção Integrada (PI) e Convencional (PC), bem como seus reflexos nos danos em frutos e plantas de cada sistema. Em ambos os anos, o uso de monitoramento na PI mostrou-se eficiente para diminuir a população a níveis baixos e dentro do limite de três aplicações de inseticidas para o controle do inseto, quando comparado com a PC. Neste tipo de produção, as aplicações foram realizadas a cada 10 dias a partir de outubro, em um total de sete aplicações no primeiro ano e nove no segundo. Com relação aos danos em frutos e ponteiros, o monitoramento na PI permitiu um controle tão eficiente quanto na PC, com a vantagem da diminuição do número de aplicações dos agroquímicos. O monitoramento mostrou-se eficiente na redução do número de aplicações de agroquímicos, com considerável redução nos custos de produção de pêssego e menor impacto sobre o meio ambiente.

Termos para indexação: Prunus persica, pêssego, monitoramento.

\section{POPULATIONAL FLUCTUATION AND CONTROL OF ORIENTAL MOTH (Grapholita molesta Busck, 1916) IN CONVENTIONAL AND INTEGRATED PRODUCTION OF PEACH-TREE}

\begin{abstract}
The present work was conducted in 2000 and 2001, in a peach-tree commercial orchard 'Marli', in the municipal district of São Jerônimo, RS, latitude $30^{\circ} 05^{\prime}$ ' $52^{\prime \prime}$ S, longitude $51^{\circ} 39^{\prime} 08^{\prime}$ ' W and altitude of 46 meters. The population of Grapholita molesta (Busck, 1916) was monitored with the goal of comparing control techniques praised in the Integrated Production system (PI) and Conventional Production system (PC), as well as its reflexes in damages of fruits and plants of each system. In both years, monitoring used in PI showed efficiency to decrease the population to low levels and among the limit of three insecticides applications for the insect control, when compared with the PC. In this kind of production, the applications were realized each 10 days begining in October, in a total of seven applications in the first year and nine in second year. With regard to the damages in fruits and pointers, monitoring in PI allowed a control so efficient as in the PC, with the advantage of decreasing the number of applications. The monitoring showed efficient reduction in chemical products applications number, with considerable reduction in the peach production costs and smaller impact on the environment. Index terms: Prunus persica, peach, monitoring.
\end{abstract}

\section{INTRODUÇÃO}

A mariposa oriental ou grafolita (Grapholita molesta) é uma das principais pragas da cultura do pessegueiro, ocasionando perdas na produção de $3 \%$ a $5 \%$, principalmente nas cultivares tardias. Além dos danos em ponteiros e frutos, a abertura provocada pela alimentação das lagartas nos frutos torna-se porta de entrada para a podridão parda. Esta doença, causada pelo fungo Monilinia fructicola, resulta em perdas adicionais durante o armazenamento dos frutos destinados ao consumo in natura (Botton et al., 2001).

Para o controle do inseto, normalmente são realizadas aplicações seqüenciais de inseticidas, sem que seja levada em consideração a população da praga nos pomares (Salles, 1998). O uso indiscriminado de agrotóxicos, visando o controle desta praga por parte dos agricultores, tem preocupado alguns segmentos da sociedade, não só sobre o aspecto de poluição ambiental mas, também, na qualidade da fruta (Grellmann et al., 1992).

A Produção Integrada de Frutas de Caroço (PI) apresenta-se como alternativa para a produção de frutas de qualidade, com a utilização de técnicas e práticas de forma integrada, com ênfase na redução de agroquímicos, priorizando métodos biológicos, culturais e físicos no controle de pragas e doenças, minimizando assim, os riscos de contaminação ambiental e da saúde humana (Fachinello et al., 2001).

Segundo Salles (1998), devem ser preconizadas práticas que favoreçam o controle biológico natural, efetuando-se o controle das pragas somente quando o monitoramento indicar a necessidade de intervenção. Além disso, na PI, foram suprimidos produtos de elevada carência (como o fenthion), os altamente nocivos aos inimigos naturais, como os piretróides, e os de alta toxicidade, como o parathion methil, além das restrições de aplicação de outros, como o dimetoato, que poderá ser aplicado somente uma vez por safra (Fachinello, 2000).

Conforme Mandail (1998), no cultivo do pessegueiro, o monitoramento da grafolita atende aos objetivos estabelecidos pelas normas para Produção Integrada de Pêssegos (PIP).

O objetivo deste trabalho foi monitorar a população da grafolita e comparar as formas de controle preconizadas no Sistema de Produção Integrada e Convencional, realizada pelo produtor, seus reflexos nos danos em frutos e na planta num pomar adulto de pessegueiro cv. Marli.

\section{MATERIALEMÉTODOS}

A comparação entre o manejo da mariposa oriental nos Sistemas de Produção Integrada (PI) e Convencional (PC) do pessegueiro realizou-se em um pomar comercial, localizado no município de São Jerônimo/RS, durante as safras 2000/2001 e 2001/2002. Utilizou-se a cultivar de mesa 'Marli'. O pomar foi dividido em duas áreas e, em cada área de 1 hectare, utilizou-se a Produção Integrada e Convencional. Os dados meteorológicos dos anos de 2000 e 2001 foram obtidos junto à Estação Agrometeorológica da Estação Agronômica da UFRGS - Eldorado do Sul.

A população da mariposa oriental (Grapholita molesta) foi avaliada nas áreas experimentais utilizando-se duas armadilhas Delta por área, contendo o feromônio sexual sintético da fêmea de grafolita. As armadilhas foram colocadas no dia 03 de março de 2000, ao acaso, a 1,8 metros do solo e a uma distância mínima de 100 metros entre os pontos de monitoramento. O septo contendo o atrativo sexual foi trocado a cada 40 dias e o piso com

${ }^{1}$ (Trabalho 163/2002). Recebido: 29/10/2002. Aceito para publicação: 30/05/2003. Financiado pelo MAPA/CNPq.

${ }^{2}$ Eng. Agr., M.Sc., Faculdade de Agronomia da UFRGS, Av. Bento Gonçalves 7712, Caixa Postal 776, CEP:91501-970, Porto Alegre, RS, e-mail: tobnunes @ ig.com.br. ${ }^{3}$ Eng. Agr., M.Sc. Prof. FZA/PUC, Câmpus II - Uruguaiana, RS, cp 249, CEP 97500-970, e-mail: roselifarias@ bol.com.br.

${ }^{4}$ Eng. Agr., Mestrando, Faculdade de Agronomia da UFRGS, Av. Bento Gonçalves 7712, Caixa Postal 776, CEP:91501-970, Porto Alegre, RS, e-mail: denissalatiguerra@zipmail.com.br.

${ }^{5}$ Estudante de Graduação, Bolsista PIBIC, Faculdade de Agronomia da UFRGS, Av. Bento Gonçalves 7712, Caixa Postal 776, CEP:91501-970, Porto Alegre, RS, email:vgrasselli@zipmail.com.br.

${ }^{6}$ Eng. Agr. Prof. Dr., Faculdade de Agronomia da UFRGS, Av. Bento Gonçalves 7712, Caixa Postal 776, CEP:91501-970, Porto Alegre, RS, e-mail: marodin@ vortex.ufrgs.br. 
cola, sempre que necessário. A flutuação populacional foi monitorada nas duas áreas, servindo como indicativo para o nível de controle (NC) no sistema Integrado. Avaliou-se o número de machos capturados semanalmente. $\mathrm{O}$ número de ponteiros brotados e os que foram atacados pela praga foram avaliados pela contagem dos mesmos em uma ramificação de cada uma das plantas marcadas de cada área, somente no ano de 2001 . O delineamento experimental utilizado foi o inteiramente casualizado (DI), com dez plantas marcadas em cada área experimental.

No sistema de Produção Integrada, o tratamento para o controle da praga realizou-se quando a população atingiu o nível de controle, 30 insetos/armadilha/semana, utilizando-se $150 \mathrm{ml}$ do produto comercial à base de fenitrotiom para cada 100 litros de água, em um tanque com 1000 litros, sendo limitada a três aplicações por safra. No sistema de Produção Convencional, os tratamentos para o controle da praga foram realizados em aplicações seqüenciais estabelecidas pelas necessidades do produtor. Utilizou-se 200 $\mathrm{ml}$ de produto comercial à base de parathion metil, em um tanque de 2000 litros. Na colheita, os danos causados pela praga foram avaliados nos frutos colhidos nas áreas experimentais.

\section{RESULTADOSEDISCUSSÃO}

O monitoramento de adultos de Grapholita molesta no pomar, tanto da PI como da PC, mostrou que o pico populacional (30 machos/ armadilha/semana), no primeiro ano de observação (2000), ocorreu no final do agosto $(25 / 08 / 00) \mathrm{e}$, posteriormente, próximo à colheita, dias 10/11/00 e 01/12/00 (Figura 1). No segundo ano de observação (2001), devido às condições climáticas favoráveis (em 2000 a temperatura média do mês mais quente foi de $24,4^{\circ} \mathrm{C}$ e a temperatura média do mês mais frio foi de $9,8^{\circ} \mathrm{C}$ enquanto que em 2001 a temperatura média do mês mais quente foi de $25,6^{\circ} \mathrm{C}$ e a temperatura média do mês mais frio de $13,8^{\circ} \mathrm{C}$ ) e, uma vez que a grafolita tem seu desenvolvimento regulado basicamente pela temperatura, sucederam-se picos populacionais na PI, sendo os mais preocupantes os que ocorreram em agosto (10/08/01), setembro (29/09/01) e novembro (09/ 11/01). Na PI, os tratamentos foram aplicados nos picos, em um limite de 3 aplicações, utilizando-se o Fenitrotion como produto, segundo recomendado pelas Normas de Produção Integrada de Frutas de Caroço (2001) em ambos os anos. Na PC, os tratamentos foram feitos segundo critério do produtor com aplicações de Parathion Methil, em um número de 7 no primeiro ano e 9 no segundo ano.

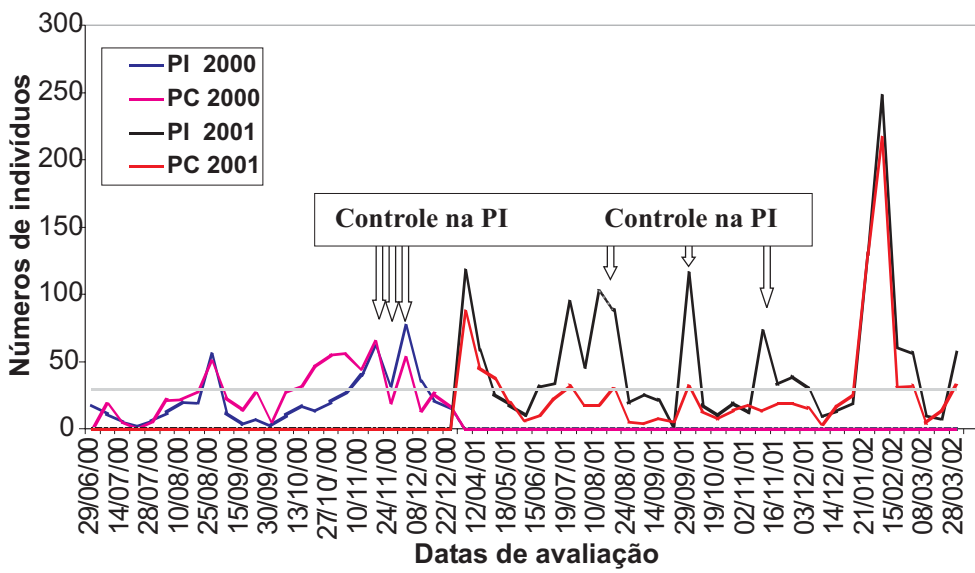

FIGURA 1 - Flutuação populacional e controle de Grafolita molesta em pessegueiro cv. Marli em sistemas de Produção Integrada e Convencional. São Jerônimo/RS. 2001. NC - nível de controle.

Em ambos os anos, o uso de monitoramento na PI mostrou-se eficiente para diminuir a população a níveis baixos e com isto diminuir o número de aplicações necessárias de inseticidas para controle do inseto. $\mathrm{Na}$ PC, o produtor fez aplicações a cada 10 dias, a partir da segunda quinzena de outubro.

Os danos ocasionados pela praga em frutos colhidos na PI, no primeiro ano, foram mais acentuados que na PC, já que a área é rodeada de pomares com cultivares precoces e que, após a colheita das mesmas, possibilitava o vôo dos insetos para a área da PI. Na primeira aplicação, ocorreram algumas falhas, uma vez que o inseticida deveria ter sido aplicado em 10/11/00, mas só o foi aplicado em 17/11/00, acentuando os danos. No segundo ano, os danos foram iguais para ambos os sistemas, devido, principalmente, às condições climáticas, que aumentou a população de grafolita nos dois sistemas. O controle da área da PI foi tão eficiente quanto o da PC, com a vantagem da redução de aplicações de produtos. O número de ponteiros brotados na PI foi superior a PC, devido a uma antecipação da poda de inverno na PI de cerca de 15 dias. Com relação aos ponteiros atacados, o monitoramento ocorreu somente no segundo ano, sendo que na PI os danos foram mais intensos que na PC, provavelmente devido ao maior intervalo entre aplicações, já que surgem a cada semana muitos ponteiros novos, sujeitos ao ataque (Figura 2). O manejo na PI permitiu que o controle da grafolita fosse feito em três aplicações, enquanto que na PC o número de pulverizações aumentou de 7 para 9 de 2000 para 2001 (Figura 2).

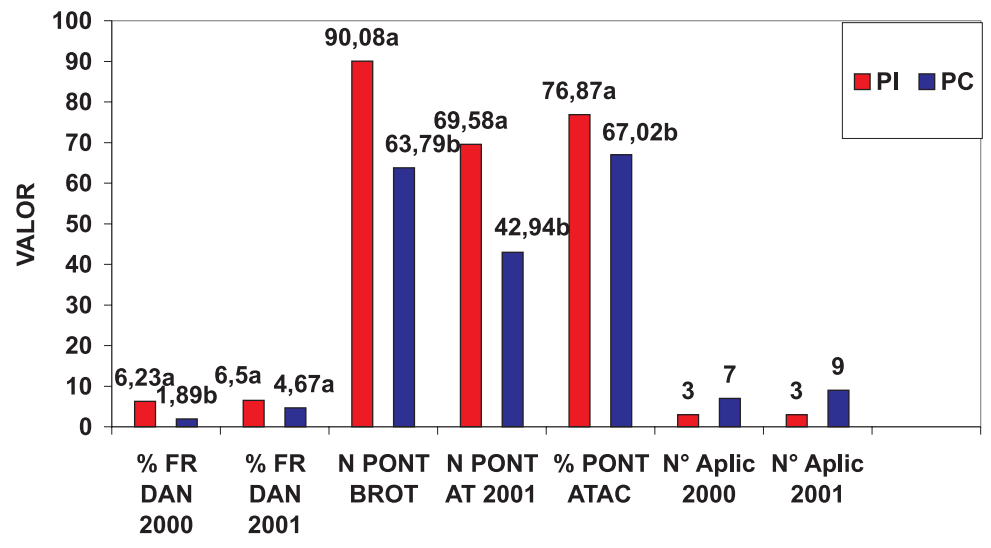

FIGURA 2 - Infestação de Grafolita molesta nos sistemas de Produção Integrado e Convencional de pessegueiro cv. Marli. São Jerônimo - RS, 2001. Percentual de Frutos danificados (\% FR Dan 2000 e 2001), Número de Ponteiros Brotados (N Pont Brot), Número de Ponteiros atacados (N Pont At 2001), \% Ponteiros Atacados (\% Pont Atac) e número de aplicacõos de inseticidas ( $\mathrm{N}^{\circ}$ Aplic 2000 e 2001). Médias seguidas de letras diferentes diferem significativamente pelo teste t a $5 \%$.

\section{CONCLUSÕES}

1) O pomar de Produção Integrada apresentou maior intensidade de danos por grafolita no primeiro ano. No segundo ano os danos foram iguais para ambos os sistemas.

2) O controle da área da PI foi tão eficiente quanto o da PC, com a vantagem da redução de aplicações de produtos.

3) O monitoramento mostrou-se eficaz na redução do número de aplicações de agroquímicos, com considerável redução nos custos de produção do pêssego, porém deve ser operado com presteza para evitar erros.

\section{REFERÊNCIASBIBLIOGRÁFICAS}

BOTTON, M.; ARIOLLI, C. J.; COLLETTA, V. D. Monitoramento da mariposa oriental, Grapholita molesta (Busck, 1916), na cultura do pessegueiro. Embrapa Uva e Vinho, 2001.p. 1-4. (Comunicado Técnico, 38)

FACHINELLO, J. C. Produção Integrada de Frutas de Caroço. In: ENCONTRO NACIONALSOBREFRUTICULTURADECLIMATEMPERADO, 3. 2000, Friburgo. Anais... p. 3-10.

FACHINELLO, J.C.; GRUTZMACHER,A.D.; FARIA, J.L.C.; HERTER, F.G; FORTES, J.F.; AFONSO, A.P.S.; TIBOLA, C.S. Avaliação agronômica de um pomar de pessegueiro conduzido no sistema de produção integrada. Revista Brasileira de Fruticultura, Jaboticabal, v.23, n.1, p. 138 $-142,2001$.

GRELLMANN,E. O.;LOECK,A.E.; SALLES,L.A.B.;FACHINELLO, J.C. Necessidades térmicas e estimativa do número de gerações de Grapholita molesta (BUSCK, 1916) em Pelotas, RS. Pesquisa Agropecuária Brasileira, Brasília, v. 27, n. 7, p. 999-1004, 1992.

MANDAIL, J. C. M. Economia da produção. In: MEDEIROS, C. A.; RASEIRA, M. C. A cultura do pessegueiro. Pelotas: Embrapa Clima Temperado, 1998.p. 340 - 350

NORMAS DE PRODUÇÃO INTEGRADADE PÊSSEGO(PIP): Versão II. Ed. Pelotas: UFPEL/EMBRAPA/UFRGS/URCAMP, 2001. 52 p.

SALLES, L. A. B. Principais pragas e seu controle. In: MEDEIROS, C. A.; RASEIRA, M. C. B. A cultura do pessegueiro. Pelotas: Embrapa Clima Temperado, 1998. p. 205-239. 